\title{
Peran Wanita Karier Dalam Pendidikan Islam
}

Igmanur Lailiyah ${ }^{1}$ Burhanuddin Ridlwan ${ }^{2}$

1,2 Universitas Hasyim Asy'ari Jombang, Indonesia

\begin{tabular}{l}
\hline Article Info \\
\hline Article history: \\
Received 2019-10-06 \\
Accepted 2020-03-27 \\
\hline
\end{tabular}

\section{Keywords:}

Women careers

Islamic education

Role play

\begin{abstract}
Along with the development of technology in various areas, brings a lot of influence in the lives of people, one of which is the role of women. In these modern times, many women who have a double profession or are commonly known as career women. And Islam also does not prohibit women to pursue a career or work outside the scope of the family, instead Islam gives a boost to women working in a field that corresponds to its ability with records not contrary to Shari'ah Islam. And also the women do not forget the responsibilities and duties in the family. If at this time women can already act in the outside world then should the career women can also play a role in the world of Islamic education. This research aims to know what is meant by career women as well as to understand its role in the world of Islamic education. The method used in this study is a library research whose data source is obtained through documentation techniques by collecting books related to the discussion of career women and Islamic education. After going through the process of analysis can be concluded that the role of a career woman in Islamic education is very important because a woman also serves as a mother in her family, it can be said that the mother is the first school for a child. Every child is born in a sacred state then it is very important the role of women in their lives in accordance with good religious doctrines and norms.
\end{abstract}

This is an open access article under the CC BY-SA license.

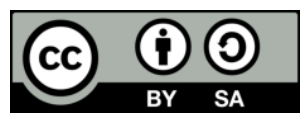

\section{Corresponding Author:}

Igmanur Lailiyah Gati

Program Studi Pendidikan Agama Islam Fakultas Agama Islam

Universitas Hasyim Asy'ari Jombang

Email: Igmalailiyah7@gmail.com

\section{PENDAHULUAN}

Munculnya modernisasi di berbagai bidang yang disertai dengan perkembangan sains dan teknologi merubah banyak sekali aktivitas dan pola gerak kaum wanita dan juga mempengaruhi ideologi serta pemikiran, begitu juga pandangan kaum wanita terhadap peran yang dahulu biasa mereka lakukan. Perkembangan zaman telah merubah pola hidup para wanita yang dulunya sebatas berdiam di rumah dan mengerjakan pekerjaan domestik, sekarang sudah banyak kaum wanita yang mandiri pada segi ekonomi dan berkarier. (Asriaty, 2014: 167-168)

Pada era globalisasi seperti ini, tentu tidak akan dapat dibendung yang namanya wanita karier. Zaman dahulu peran kaum wanita hanya sebatas pekerjaan di dalam rumah tangga, layaknya melayani suami, mengurus pekerjaan dalam rumah, dan mendidik anak. Saat ini, sudah banyak terjadi perubahan pada peran wanita. Wanita sudah tidak merasa puas dengan pekerjaan rumah tangga, sehingga tidak sedikit wanita yang terjun ke dalam dunia karier. Masalahnya, saat wanita memilih berkarier utamanya bagi wanita yang sudah berumah tangga, ia akan mendapatkan peran ganda yang akan menimbulkan persoalan baru yang rumit. Selain tuntutan melaksanakan kewajiban dalam rumah tangga, ia juga memiliki tanggung jawab menyelesaikan tugasnya dalam pekerjaan. (Siti Ermawati, 2016: 59-60)

Duxbury dan Higgins menyatakan bahwa beban dan peran ganda akan didapatkan oleh para wanita yang terjun dalam dunia kerja. Sebuah situasi yang susah diselesaikan dapat timbul karena tuntutan lebih yang disebabkan oleh peran ganda yang didapatkan. Kedua peran tersebut menuntut kinerja yang sama 
baiknya, jika wanita lebih mengutamakan karier pekerjaannya maka hal itu dapat mengorbankan banyak hal untuk keluarganya. Agar tercipta sebuah kehidupan yang bermakna dan berkualitas, seorang individu membutuhkan sebuah keseimbangan antara pekerjaan dan kehidupan keluarganya. Wanita yang terjun dalam dunia karier perlu mencapai keseimbangan ini, yakni keseimbangan antara kehidupan dan pekerjaannya. (Marina Dwi Mayangsari, 2018: 44)

Sejalan dengan pesatnya laju perkembangan zaman dan teknologi, peran wanita pada saat ini semakin maju dan berkembang. Jumlah wanita karier di Indonesia semakin meningkat. Khususnya di berbagai kota besar, wanita cenderung memilih berperan ganda bahkan ada yang multifungsional dikarenakan mereka mendapatkan lebih banyak kesempatan untuk mengembangkan diri. Peran wanita bukan hanya dalam pendidikan tetapi lebih jauh terlibat dalam karier ekonomi, bisnis maupun politik. Jaminan untuk sukses secara finansial, diakui eksistensi dan menyandang predikat mandiri mengharuskan menjemput impian dengan mendapatkan posisi yang tinggi dalam dunia pekerjaan.

Tidak ada larangan secara mutlak wanita untuk berkarier. Banyak yang dilakukan wanita pada masa sekarang menjadi wanita karier sedangkan di sisi lain wanita mempunyai peran sebagai ibu dan istri yang mengharuskan wanita untuk tetap di rumah. Bekerja di dalam Islam merupakan hak setiap muslim terbuka bagi siapa pun selama mereka menginginkannya dan pekerjaan tersebut tidak mendatangkan bahaya.

Dalam Islam karier wanita harus bertujuan baik seperti untuk mendidik wanita dan anak-anak. Akan tetapi yang banyak dijumpai justru tidak demikian, wanita yang berkarier di dunia luar mereka cenderung lebih banyak menghabiskan waktunya untuk karier dan mereka lebih memprioritaskan kenaikan jabatan dari pada menghabiskan waktu di rumah bersama dengan keluarganya. jika hal ini terjadi terus menerus maka akan terjadi permasalahan yang rumit dalam kehidupan rumah tangganya. Ada beberapa faktor yang bersifat intern yang mendorong para wanita bekerja diluar rumah. Beberapa faktor tersebut diantaranya sebagai berikut: Pendidikan, ttuntutan hidup, ingin punya penghasilan sendiri.

Melihat realita yang terjadi sebagaimana yang telah dipaparkan, inilah yang menarik perhatian penulis untuk mengadakan penelitian terkait wanita karier dan peranannya untuk dijadikan fokus penelitian untuk menyelesaikan tugas yakni skripsi dengan judul: Peran Wanita Karier Dalam Pendidikan Islam. Dari latar belakang di atas dapat ditarik kesimpulan, bahwa penelitian ini fokus pada dua unsur yakni 1) apa yang dimaksud dengan wanita karier? 2) bagaimana peran wanita karier dalam pendidikan Islam? Tujuan Penelitian 1) mendeskripsikan pengertian wanita karier, 2) Mendeskripsikan peran wanita karier dalam pendidikan Islam.

Dalam KBBI, “ wanita” memiliki arti perempuan dewasa, sedangkan "wanita karier” memiliki arti wanita mandiri dalam kegiatan profesi. (Depdikbud, 2008: 372). Karier adalah profesi yang menjanjikan untuk sukses, karena karier memiliki keuntungan yang sangat besar. namun karier juga harus sesuai bidang yang ditekuni, karena bila kita melakukan pekerjaan sesuai dengan bidang yang kita tekuni maka akan menikmati hidup bahagia. Wanita karier untuk saat ini bukan hal yang asing lagi karena bukan hanya lakilaki yang dapat menyalurkan karyanya. (A. Nunuk, 2004: 217). Syarat wanita karier yaitu melakukan pekerjaan halal, berperilaku sesuai dengan aturan syariat Islam dalam hal berpakaian, berjalan, dan berbicara, pekerjaannya tidak boleh membuatnya lupa dari tugas dan kewajibannya sebagai ibu rumah tangga. (Rizem Aizid, 2006: 47). Wanita karier memiliki beberapa keuntungan bagi keluarga, antara lain:

keuntungan ekonomi. Wanita bekerja untuk mencari nafkah tambahan demi kesejahteraan keluarganya yang lebih baik. Wanita juga merencanakan, meningkatkan pemeliharaan dan mendistribusikan penghasilan keluarga untuk meningkatkan dan melangsungkan kesejahteraan keluarga. Keuntungan perlindungan. Wanita berperan menghindarkan anggota keluarga dari situasi atau tindakan yang dapat membahayakan atau menghambat kelangsungan hidup, pertumbuhan dan perkembangan secara wajar. Keuntungan pendidikan. Wanita berperan untuk meningkatkan mutu, kualitas, sikap anggota dalam keluarga sesuai dengan norma untuk menjadikan keluarga yang makmur.

Keuntungan sosialisasi, berperan untuk lebih mengenal lingkungan di dalam anggota keluarga maupun lingkungan luar. Dengan adanya keuntungan ini kita dapat berbaur lebih dengan anggota keluarga di luar lingkungan. Keuntungan agama, wanita sebagai penghubung atau contoh teladan baik bagi anggota keluarga. Karna ilmu keagamaan dapat mempengaruhi sikap, perilaku seseorang. Oleh sebab itu ilmu keagaan penting untuk semua anggota keluarga untuk mencapai Lilah dari sang maha kuasa.

Keuntungan afeksi, perilaku yang dikembangkan oleh sosial lingkungan dan sikap yang ada dalam diri manusia itu sendiri. (Iklima, 2014: 6). Pendidikan islam adalah materi yang berhubungan dengan keagamaan atau sikap religious terhadap keyakinannya. Jadi pendidikan islam itu lebih condong dalam memperbaiki sifat dalam diri manusia dan di wujudkan dengan sikap atau perbuatan baik buruk manusia itu sendiri. (Dayun, Nurlaili, 2017: 10). Pendidikan sebagai bentuk usaha manusia untuk mencapai tujuan hidup yang baik dengan berlandaskan al qur an dan hadist serta sesuai dengan aturan-aturan lingkungan sosial. Yang dapat berkembang sesuai maslahat umah. 


\section{METODE}

Adapun metode yang telah digunakan penulis dalam penelitian ini yaitu; jenis penelitian, jenis data, sumber data, teknik pengumpulan data, teknik analisis data seta metode pendekatan. Yang akan dijabarkan dibawah ini sebagai berikut; Penelitian kali ini menggunakan metode telaah pustaka atau biasa dikenal dengan istilah (library reseach) dengan menggunakan teknik pengumpulan data dokumentasi yaitu dengan mengumpulkan literature ataupun buku-buku yang membahas hal yang berkaitan dengan wanita karier serta peranannya dalam pendidikan. Jika dilihat dari jenis data yang diperoleh penelitian ini dapat dikategorikan dalam penelitian kualitatif yang mana sumber data utamanya adalah buku dan dijabarkan menggunakan metode deskriptif, sedangkan analisis yang digunakan di sini merupakan analisis deduktif yaitu menjabarkan hal yang umum terlebih dahulu kemudian mengarah pada permasalahan yang khusus melalui pendekatan deskriptif kualitatif,

\section{HASIL DAN PEMBAHASAN}

Setelah mempelajari dan mengaji sumber data primer dan sekunder, maka penulis mencoba untuk menganalisis pengertian wanita karier dan peranannya dalam dunia pendidikan Islam. Wanita Karier Dalam Perspektif Pendidikan Islam. Wanita karier merupakan wanita yang menekuni dalam suatu bidang profesi atau kegiatan profesi seperti bidang usaha atau perkantoran dalam rangka untuk meningkatkan hasil prestasi dan keterampilannya. Sebagai wanita karier yang mempunyai keahlian dalam bidang tertentu juga mempunyai peran ganda yaitu sebagai ibu dalam keluarga. Wanita karier akan menjadi idola anak, dengan berkarier akan menciptakan peran yang lebih aktif yang dapat memicu anggota keluarga untuk mempunyai tanggung jawab tugas di dalam rumah dan menuntut anak menjadi pribadi yang mandiri.

Wanita karier menekuni dan memerankan dirinya untuk mewujudkan jati dirinya dan membangun kepribadiannya secara sempurna dengan meningkatkan keahliannya dibidang tertentu agar dapat menunjang kehidupan dan jabatannya. Jenjang wanita karier pada umumnya berkiprah diluar rumah akan membuka kesempatan bagi wanita karier untuk berkembang dan mengaktualisasikan dirinya akan semakin terbuka bersamaan dengan semakin tingginya tingkat pendidikan mereka

Mencermati dari penjelasan yang telah diuraikan diatas dapat dikatakan bahwa karier bukan hanya sekedar pekerjaan biasa tetapi merupakan sebuah interes seseorang terhadap apapun yang telah ditekuninya dalam jangka yang cukup panjang dan telah dilakoninya dengan sungguh-sungguh agar dapat mencapai kedudukan yang tinggi hingga mereka akan dapat mencapai kemandirian ekonomi.

Dengan begitu dapat ditarik kesimpulan bahwasanya wanita karier merupakan seorang wanita yang mendalami suatu bidang tertentu yang memang sesuai dengan bakat dan minatnya. Hal ini dilakukan dengan tujuan agar dapat mencapai kedudukan yang tinggi, mencapai prestasi yang membanggakan sehingga mereka mendapatkan kepuasan tersendiri dalam kehidupannya. Dari penjelasan tersebut dapat disimpulkan ciri wanita karier sebagai berikut: Pertama, Wanita yang mendalami suatu bidang dan berkutat dalam pekerjaan yang sesuai dengan hobinya, dengan tujuan untuk mengembangkan bakat sehingga dapat meningkatkan kariernya. Kedua, Wanita yang memilih berprofesi ganda demi meningkatkan ekonomi dalam keluarganya dikarenakan menginginkan adanya kesejahteraan dalam kehidupan serta perbaikan dalam strata sosial. Ketiga, Wanita yang bekerja menargetkan suatu kemajuan bagi pekerjaannya dan meningkatkan keahliannya dalam bidang yang dikuasainya. Keempat, Wanita yang cukup aktif mengadakan kegiatan untuk mencapai suatu peningkatan dalam mengembangkan keahlian yang dimiliki dan profesionalitasnya.

\section{Peran Wanita Karier Dalam Pendidikan Islam}

Peranan wanita karier dalam dunia pendidikan Islam ada tiga yaitu :Wanita sebagai ibu.

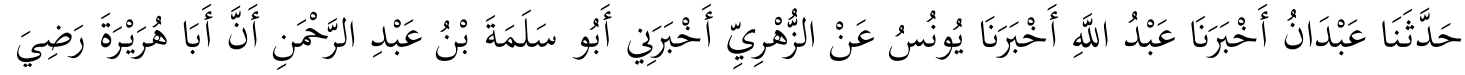

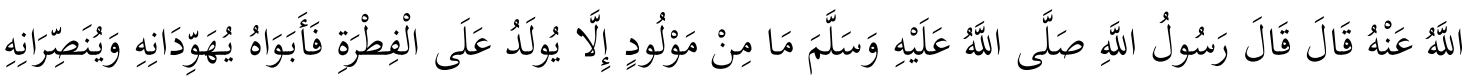

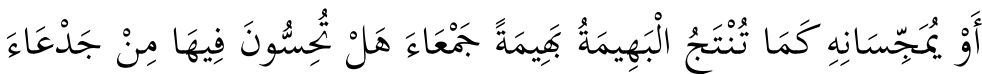

“Abdân menceritakan kepada kami (dengan berkata) 'Abdullâh memberitahukan kepada kami (yang berkata) Yunus menceritakan kepada kami (yang berasal) dari al-Zuhri (yang menyatakan) Abu Salamah bin 'Abd al-Rahmân memberitahukan kepadaku bahwa Abu Hurairah ra berkata: Rasulullah saw bersabda: "Setiap anak lahir (dalam keadaan) fitrah, Kedua orang tuanya (memiliki andil dalam) menjadikan anak beragama Yahudi, Nasrani, atau bahkan beragama Majusi, sebagaimana binatang ternak memperanakkan seekor binatang (yang sempurna anggota tubuhnya). Apakah anda melihat anak binatang itu ada yang cacat 
(putus telinganya atau anggota tubuhnya yang lain)? (HR. al-Bukhâri). Wanita karier selain bekerja untuk meningkatkan karier dan keahliannya, juga menjadi seorang ibu dalam keluarganya, yaitu mendidik anak. Karena ibu mempunyai ikatan yang khusus dan paling dekat dengan batin sang anak. Sebagai wanita karier harus bisa memosisikan ketika dalam keluarganya sebagai seorang ibu yaitu mendidik dan menyayangi anaknya. Harus mempunyai tanggung jawab khusus untuk memonitoring dan mengembangkan kepribadian anak khususnya dalam pendidikan agama, pendidikan Islam harus tertanam dalam jiwa anak sedini mungkin termasuk ketauhidan.

Sebagai Istri. Wanita karier pada saat ini juga mempunyai peran sebagai seorang istri, ketika diluar berperan sebagai wanita karier tapi dalam keluarga harus bisa memosisikan sebagai perannya seorang istri terhadap suami. Wanita sebagai mitra suami diharuskan bisa menjalankan tiga peran dalam waktu bersamaan. Yaitu sebagai istri, teman ataupun kekasih. Dengan melayani suami sebagai mestinya yang merupakan hak seorang istri. Selain itu ketika berhadapan dengan suami bersikap lemah lembut, meskipun menjadi seorang wanita karier yang mempunyai keahlian atau pendidikan tinggi ketika berperan sebagai seorang istri di hadapan suami harus bisa memosisikan dirinya sebagai seorang istri, jika ada masalah dapat berdiskusi dan memecahkan masalah dengan suami dengan pikiran yang terbuka, tidak membentak suami maupun bersikap mempunyai kedudukan tinggi diatas suami, karena suami tetap menjadi kepada keluarga di dalam rumah tangga. Wanita karier dituntut untuk menjadi partner dan seorang professional di tempatnya berkarier.

Wanita sebagai pribadi dan anggota masyarakat. Wanita karier sebagai pribadi yang sukses merupakan bagian dari anggota masyarakat yang dianggap mampu mengayomi masyarakat.

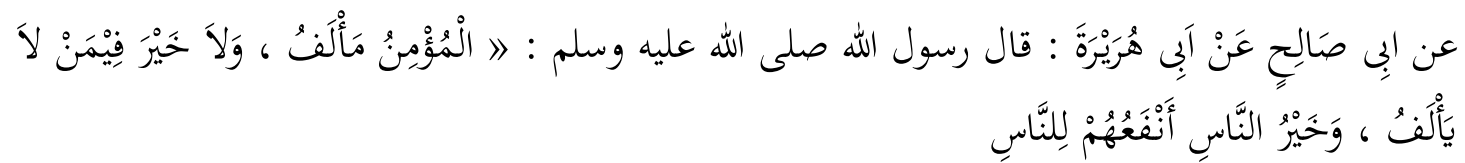

Dari Jabir, ia berkata,'Rasulullah Saw bersabda,'Orang beriman itu bersikap ramah dan tidak ada kebaikan bagi seorang yang tidak bersikap ramah. Dan sebaik-baik manusia adalah orang yang paling bermanfaat bagi manusia." (HR. Thabrani dan Daruquthni). Wanita karier dengan segala pengetahuan dan kemampuannya diharapkan dapat membantu meningkatkan pengembangan pendidikan di masyarakat. Dengan mengadakan kegiatan yang bisa membawa kebaikan bagi masyarakat dilingkunganya.

\section{KESIMPULAN}

Setelah melalui analisis yang panjang sebagaimana telah dijabarkan dalam bab sebelumnya maka dapat ditarik kesimpulan sebagai berikut: Pengertian wanita karier. Wanita yang menekuni kegiatan bidang tertentu yang mana hal ini dilakukan dengan tujuan agar dapat meningkatkan kemampuannya serta memperoleh apa-apa yang memang mereka ingin capai dalam kehidupannya, seperti kedudukan yang tinggi, ekonomi yang mapan serta prestasi yang memuaskan dalam bidang yang memang mereka tekuni. Peran wanita karier dalam pendidikan Islam yaitu wanita sebagai ibu, wanita sebagai istri, dan wanita sebagai pribadi dan anggota masyarakat. Wanita sebagai ibu, Sebagai wanita karier harus bisa memosisikan ketika dalam keluarganya sebagai seorang ibu yaitu mendidik dan menyayangi anaknya. Harus mempunyai tanggung jawab khusus untuk me monitoring dan mengembangkan kepribadian anak khususnya dalam pendidikan agama Islam. Wanita sebagai istri, Wanita sebagai mitra suami harus mampu mewujudkan tiga peran sekaligus. Yakni sebagai istri, sahabat dan kekasih. Keluarga merupakan tanggung jawab utama wanita karier bekerja sama dengan suami dalam peran menyampaikan pendidikan Islam di keluarga.

\section{REFERENSI}

Aminah, Mia Siti. Muslimah Career, Yogyakarta: Pustaka Grhatama, 2010.

Aizid, Rizem. Fiqih Islam bagi Muslimah Kerier, Yogyakarta: Noktah, 2018.

Baswedan, Aliyah Rasyid. Wanita, Karier \& Pendidikan Anak. Yogyakarta: Ilmu Giri,2015

Daradjat, Zakiah, dkk. Ilmu Pendidikan Islam, Jakarta: Bumi Aksara, 2014.

Hafidz Anshary A,Z dan Huzaimah T, Yanggo, Ihdad Wanita Karier dalam Problematika Hukum Islam Kontemporer, Cet III. Jakarta:Pustaka Firdaus, 2002.

Isnaini Muhammad. Diskurs Wanita Dalam Pergolakan Modernitas, Yogyakarta: IDEA Press,2009

Muhammad bin Ismail abi Abdullah Al-Bukhori Al-Ja'fi. Al-jami’ul Musnad Ash-Shohih Al-Mukhtashor , Darut Tauqi an-Najah: Muhammad Zuhairy bin Nashir,1442H

Muri'ah, Siti. Nilai-Nilai Pendidikan Islam dan Wanita Karier, Semarang: Rasail Media Group, 2011. 
Nurlaili Riadi Dayun dan Junaidi Hamzah. Ilmu Pendidikan Islam, Yogyakarta: Pustaka Pelajar 2017. Sugiyono, Metode Penelitian Pendidikan, Pendekatan Kuantitatif, Kualitatif dan R \& D, Bandung: Alfabeta, 2017.

Sukmadinata, Nana Syaodih. Metode Penelitian Pendidikan, Bandung: PT Remaja Rosdakarya,2009.

Tim Media, Undang-Undang SISDIKNAS (Sistem Pendidikan Nasional), Bandung: Fokus Media, 2015 Thalib, Muhammad. Solusi Islami Terhadap Dilema Wanita Karier, Yogyakarta: Wihdah Press, 2004. Utaminingsih, Alifiulahtin. Gender dan Wanita Karier, Malang: UB Press, 2017. 